\title{
Conservation of small hairtail Trichiurus japonicas by using hooks with large artificial bait: effect on the trolling line fishery
}

\author{
Taro Hirose $^{1,4} \cdot$ Masaki Sakurai $^{1,2} \cdot$ Shingo Watari $^{3} \cdot$ Michio Ogawa $^{1}$. \\ Mitsutaku Makino ${ }^{3}$
}

Received: 31 January 2017 / Accepted: 14 September 2017 / Published online: 1 November 2017

(C) The Author(s) 2017. This article is an open access publication

\begin{abstract}
Overfishing has reduced the stock of hairtail Trichiurus japonicus around the Bungo Channel, Japan. To determine whether using larger bait in the trolling line fishery could avoid catching small/undersize hairtail, we developed and trialled a new large artificial bait (a soft plastic bait, 6 inches long). A traditional lure with natural bait (type-1), a new lure of the new artificial bait hook without natural bait (type-2), and a new lure with natural bait (type3 ) were tested in fishing operations around the Bungo Channel. Compared with type-1, type- 2 and type- 3 caught fewer
\end{abstract}

Taro Hirose

taro@affrc.go.jp

Masaki Sakurai

masaki-sakurai@pref.kagoshima.lg.jp

Shingo Watari

swatari@affrc.go.jp

Michio Ogawa

ogawa@jamarc.go.jp

Mitsutaku Makino

mmakino@affrc.go.jp

1 Marine Fisheries Research and Development Center, Japan Fisheries Research and Education Agency, 15F Queen's Tower B, 2-3-3 Minatomirai, Nishi-ku, Yokoham, Kanagawa 220-6115, Japan

2 Kagoshima Prefectural Fisheries Technology and Development Center, 160-10, Iwamoto, Ibusuki, Kagoshima 891-0315, Japan

3 National Research Institute of Fisheries Science, Japan Fisheries Research and Education Agency, 2-12-4, Fukuura, Kanazawa-ku, Yokohama, Kanagawa 236-8648, Japan

4 Present Address: National Research Institute of Fisheries and Environment of Inland Sea, Japan Fisheries and Education Agency, 2-17-5, Maruishi, Hatsukaichi, Hiroshima 739-0452, Japan undersized and immature female individuals. The number of fish caught, yield, and composition of commercial size grades per recruitment were calculated from field data for each lure and compared. The catch sizes (number of fish per recruitment) were smaller for type- 2 and type- 3 than for type-1, but yield per recruitment was higher for type-3 than for type-1. Compared with type-1, type-2 and type- 3 caught more large individuals, which are more valuable. The newly developed artificial bait conserves hairtail stocks by targeting larger fish, which is economically beneficial for the hairtail trolling line fishery.

Keywords Size selectivity $\cdot$ Stock conservation

\section{Introduction}

Hairtail Trichiurus japonicas is an important commercial target species in Japan, and is found in waters from Hokkaido to the Yellow Sea, the Bo Hai Sea, and the East China Sea [1]. Hairtail yields greater than $60,000 \mathrm{t}$ were recorded in the 1960s in Japan, while recent catches have fluctuated between 8000 and 20,000 t [2]. From the 1960s to the 1980s, the catch from the East China Sea markedly decreased [1], so the relative importance of the Bungo Channel in Japan as a hairtail fishing ground has increased. The yield from the Bungo Channel area (Oita and Ehime Prefectures) has accounted for $30-40 \%$ of the total hairtail catch in Japan in recent years [3].

The trolling line fishery targeting hairtail is a common fishery in western Japan, harvesting $40 \%$ of the total annual hairtail catch in Japan. The Bungo Channel is one of the most important trolling line fishing areas for hairtail, and fishers in Oita and Ehime Prefectures mainly target this area. The annual yield of the hairtail trolling line fishery has been 
1500-4000 $\mathrm{t}$ in recent years [4]. However, the stock level of hairtail in this area has decreased recently [4, 5], and stock enhancement programs have been implemented by fishers and local government [6]. One such enhancement program is to regulate the body size of hairtail caught by the trolling line fishery. In Oita Prefecture, the lower hairtail body weight limit is $200 \mathrm{~g}$, and fishers must release fish lighter than this. In many cases, however, hairtail with a relatively large air bladder are fished from $>100-\mathrm{m}$ depths in the Bungo Channel, and many of these are seriously damaged. To explore the effects of the regulations, approximately 1500 tagged hairtail individuals were released in 2013 and 2014, but few have been recaptured, and the effect of the regulations is thought to be limited [7]. On the other hand, using large natural and artificial bait was shown to reduce the catch rate of smaller hairtail $[2,7]$. Reducing the catch of smaller hairtail means that a larger population remains to grow into fish of an acceptable size.

We developed a new large artificial bait for the hairtail trolling line fishery to protect small fish and increase the hairtail stock level. We compared body size composition of captured hairtail between a traditional lure used in the Bungo Channel and newly developed lures with the new large artificial bait. We compared catches in terms of the number per recruitment (NPR) and yield per recruitment (YPR) among lures, because the effect of leaving small individuals on the hairtail stock could not be described by a simple comparison of catch per unit effort (CPUE). We also examined the composition of commercial size grades per recruitment (GPR), because this directly affects the income of fishers. Through these comparisons, we discuss the effect of the new bait for the conservation of small-size hairtail and the impact of this on the hairtail fishery.

\section{Materials and methods}

\section{Lure types}

The fishing lure used most commonly by the trolling line fishery around the Bungo Channel consists of artificial bait (a 5-inch soft plastic bait, cut in half), hook (total length, $8.0 \mathrm{~cm}$; front length, $2.0 \mathrm{~cm}$; width, $2.0 \mathrm{~cm}$ ) with a sinker (3.75-11.25 g), and natural bait (sand eel Ammodytes personatus) (Fig. 1) (type-1). Two new types of lure were developed: type-2, which comprises artificial bait (6-inch soft plastic bait) and hook (total length, $9.0 \mathrm{~cm}$; front length, $2.3 \mathrm{~cm}$; width, $2.0 \mathrm{~cm}$ ) with a sinker (the same as for type1 ); and type-3, which is the same as type-2, except that it is baited with natural bait (sand eel). The 6-inch soft plastic bait used in type-2 was developed especially for this study. Its shape and materials were similar to those of the 5-inch lure (Power Shad Strong; Marukyu, Japan) to retain the fishing performance of the 5-inch lure.

\section{Fishing tests in the field}

Fishing tests were conducted from 1 August to 30 November 2013 at Usuki in Oita Prefecture, the home port (Fig. 2). The study area depth was 100-200 $\mathrm{m}$ in the Bungo Channel. The vessel was the Koryo-Maru (FRP 4.2 t). The data analysed in this study were collected during the actual operations of Koryo-Maru during the study period. The troll rig consisted of the main line $(320 \mathrm{~m})$ and 80 branches (length of line $3 \mathrm{~m}$ ) at intervals of $3,3.5$ or $5 \mathrm{~m}$, with several types of lure and two or three small floats (5-6 cm in diameter) [2]. A series of operations was carried out as follows: first, the rig was sunk to near the seafloor with wire attached to the head of the main line and sinker attached to the head of the wire [2], which was unwound to the layer where hairtail echograms were detected. The length of wire could not be known accurately on the troller, so the fisher sunk the sinker to the seafloor and then wound the wire according to the number of rotations of the wire reel. After trolling for 15-30 min at 2 knots, the gear was hauled up onto the troller and the captured hairtail were brought in.

During the study period, fishing operations with type-1, type-2, and type- 3 were conducted 126, 157, and 215 times, respectively. When using type-2, other lures with natural bait were not used to avoid attracting fish to these. The preanal length (PAL) of hairtail caught was recorded for each lure type on board. The PAL (intervals of $1 \mathrm{~cm}$ ) for each lure type throughout the study period was also calculated. As described in the Introduction, $200 \mathrm{~g}$ body weight is the smallest commercial size for hairtail in Oita Prefecture. This weight corresponds to $25-\mathrm{cm}$ PAL [8]. Therefore, the proportions of individuals considered of commercial size were calculated from the PAL composition for each lure.

\section{Catch per unit effort}

The CPUE (individuals/hook) of each lure for every size class of PAL was calculated from the PAL composition and total number of hooks for each lure used during the study period. Then, the ratio of CPUE of type- 2 and type- 3 to that of type-1 was calculated for every size class.

\section{Catch in terms of NPR, YPR, and composition of commercial size GPR}

According to the methods and results of the stock analysis described by Watari et al. [4], catch in NPR and YPR for type-1, type-2, and type-3 were calculated. The hairtail fishery around the Bungo Channel can be broadly divided into two types: the trolling line fishery, and net fisheries 
Fig. 1 Lures used in this study. a Type-1: 5-inch soft lure cut in half, hook with sinker (d) and natural bait (f). b Type-2: 6-inch soft lure and hook with sinker (e). c Type-3: same type of lure and hook as Type-2, with natural bait. d Hook with sinker for Type-1. e Hook with sinker for Type-2 and 3. f Natural bait: sand eel Ammodytes personatus (a)

$$
\text { approx. } 6.3 \mathrm{~cm}(5 / 2 \mathrm{inch})
$$

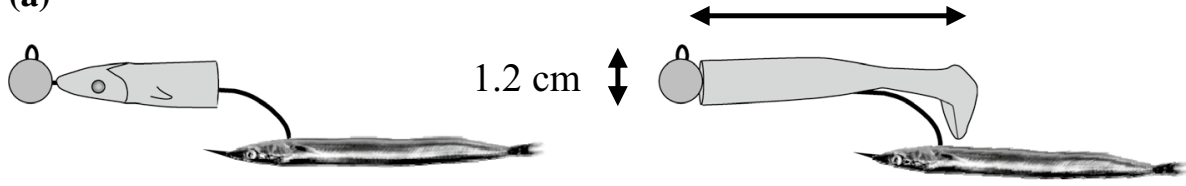

$15.2 \mathrm{~cm}(6$ inch $)$

(b)

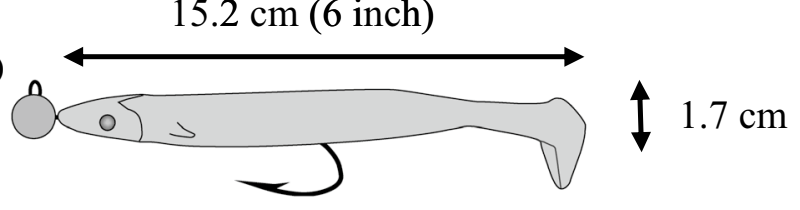

(c)

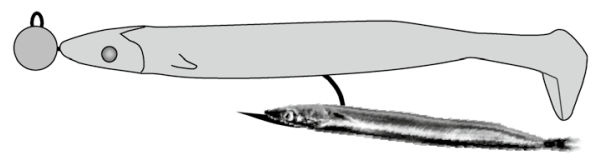

(d)

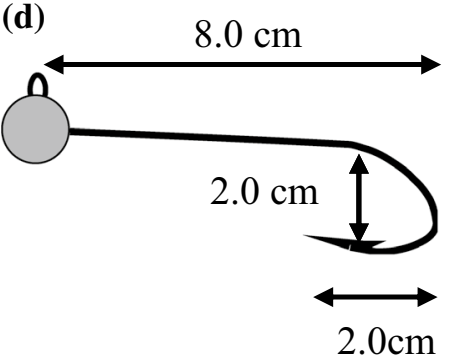

(e)

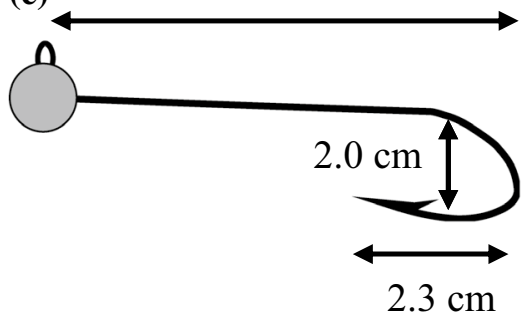

(f)

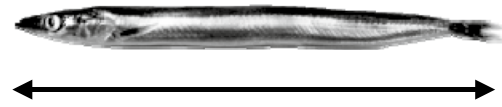

$7.5 \sim 10.0 \mathrm{~cm}$

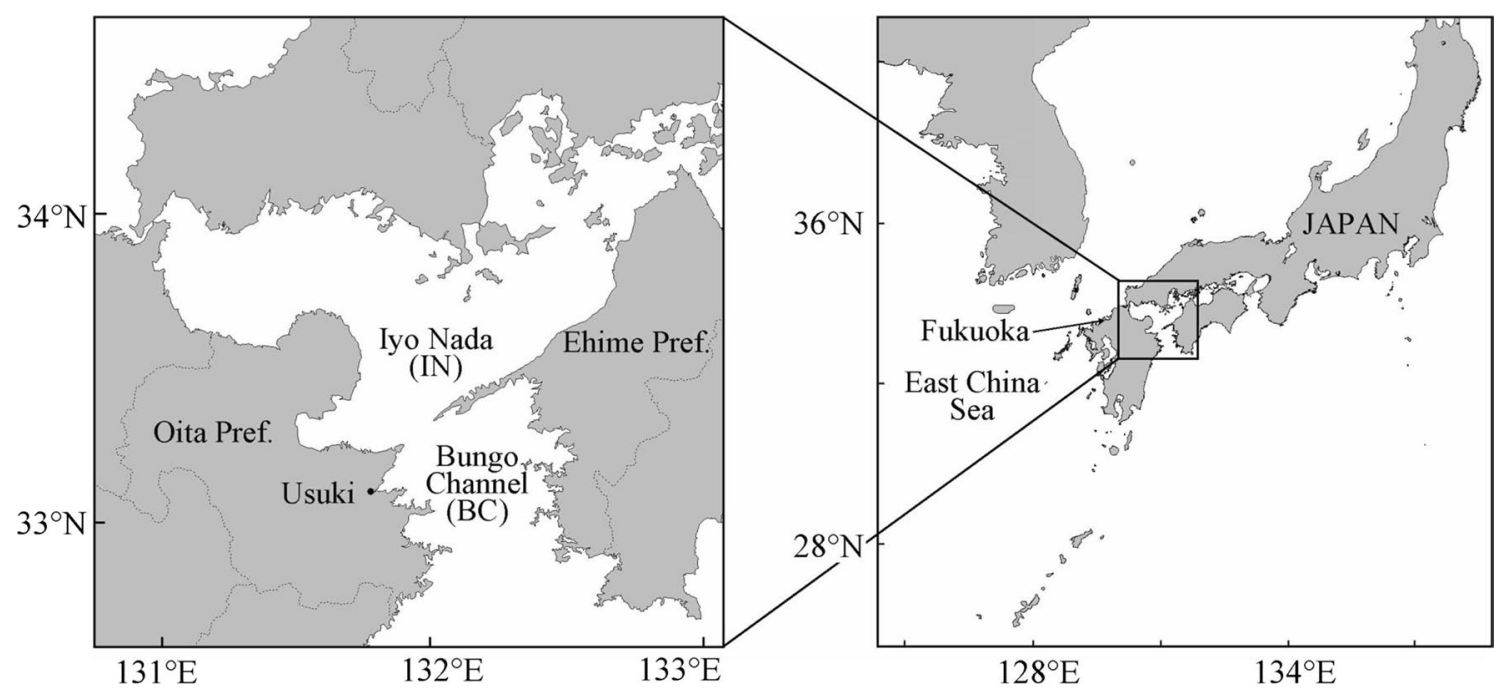

Fig. 2 Study sites, Iyo Nada and Bungo Channel 
(bottom trawl and purse seine). In this analysis, the mortality of hairtail around the Bungo Channel was categorized into four classes: mortality due to trolling line fishery, discard of trolling line fishery, discard of net fisheries, natural mortality. Although undersize hairtail caught by trolling line were released, we assumed that all of them were dead after release. The natural mortality coefficient and fishing mortality coefficients for 2011, when the new large artificial bait had not yet been developed, were obtained from Watari et al. [4] and used in this calculation.

Catch in NPR for type-1, type-2, and type-3 was calculated as follows:

$$
\begin{aligned}
N P R_{t}= & \sum_{S=1}^{2} \sum_{a=1}^{A_{s}} \frac{F_{s, a, T C(t)}}{F_{s, a, T C(t)}+F_{s, a, T D(t)}+F_{s, a, P C}+M} \\
& \times\left\{1-\exp \left(-F_{s, a, T C(t)}-F_{s, a, T D(t)}-F_{s, a, P C}-M\right)\right\} S_{s, a} \\
S_{s, a+1}= & S_{s, a} \exp \left(-F_{s, a, T C(t)}-F_{s, a, T D(t)}-F_{s, a, P C}-M\right)
\end{aligned}
$$

where $t$ is the lure type. $F_{s, a, f}$ is fishing mortality coefficient of the brood $s$ (1, spring brood; 2, autumn brood), at accumulated term $a$ and of fishery type $f$ (TC, trolling line; TD, discard of trolling line; PC, net fisheries). We divided 1 year into three terms based on life cycle of hairtail, and the maximum accumulated term of the spring brood $(A 1)$ is 17 and that of the autumn brood (A2) is 16. [4]. $M$ and $S_{s, a}$ indicate natural mortality coefficient and stock number, respectively, and $S_{1,0}$ and $S_{2,0}$ are the number of recruits from the spring and autumn brood, respectively. In this study, we assume $S_{1,0}=8$ and $S_{2,0}=11$ according to the recruitment levels of both broods in 2011. The fishing mortality coefficient of discards from the trolling line was calculated as follows:

$F_{s, a, T D(t)}=\frac{\left(1-\delta_{s, a}\right) F_{s, a, T C(t)}}{\delta_{s, a}}$

where $\delta_{s, a}$ is the proportion of commercial-size fish out of the total catch. $\delta_{s, a}$ was calculated according to the average $\operatorname{PAL}\left(L_{s, a}\right)$ and variance by the age-length relationship from Watari et al. [8]:

$\delta_{s, a}=\int_{25}^{\infty} \frac{1}{\sqrt{2 \pi \sigma_{s}}} \exp \left\{-\frac{\left(x-L_{s, a}\right)^{2}}{2 \sigma_{s}^{2}}\right\} \mathrm{d} x$

where $x$ is the variable of PAL and $\sigma_{s}$ is the SD of the agelength relationship for each seasonal brood.

In 2011, the total fishing mortality of the trolling line fishery, including discards, was attributed to fishing by type- 1 because these lures accounted for more than $90 \%$ of all lures used around the Bungo Channel. Therefore, the $F_{s, a, T C(1)}$ could be assumed to be the actual $F_{s, a}$ of the trolling line fishery in 2011. Then, $F_{s, a, T C}(2$ or 3 ) was calculated as follows: two regression lines were derived from the ratio of CPUE of type- 2 and type- 3 for PALs (mid-point of each size class). CPUE $>36 \mathrm{~cm}$ PAL was excluded from these analyses because of the small sample size. The PAL of the seasonal brood $s$ at accumulated term $a$ derived from the age-length relationship [8] was substituted into regression equations to calculate the ratio of $\mathrm{CPUE}_{s, a, t}$ for type-2 and type-3 lures. Both spring and autumn broods reached $25-\mathrm{cm}$ PAL (lower limit size) at accumulated term 5, and 35-cm PAL at accumulated term 8 . For both lure types, the CPUE values of $>36-\mathrm{cm}$ PAL were fixed at those for $35-\mathrm{cm}$ PAL, which were calculated from regression equations. Then, $F_{s, a, T C}(2$ or 3 ) was calculated as follows:

$F_{s, a, T C(2 o r 3)}=F_{s, a, T C(1)} \frac{C P U E_{s, a, 2 o r 3}}{C P U E_{s, a, 1}}$.

$F_{s, a, T C \text { (2 or 3) }}$ was substituted for Eq. (1) and $\mathrm{NPR}_{(2 \text { or 3) }}$ was calculated.

The YPR of each lure type $\left(\mathrm{YPR}_{t}\right)$ was calculated as follows:

$$
\begin{aligned}
Y P R_{t}= & \sum_{S=1}^{2} \sum_{a=1}^{A_{s}} \frac{F_{s, a, T C(t)}}{F_{s, a, T C(t)}+F_{s, a, T D(t)}+F_{s, a, P C}+M} \\
& \times\left\{1-\exp \left(-F_{s, a, T C(t)}-F_{s, a, T D(t)}-F_{s, a, P C}-M\right)\right\} S_{s, a} W_{s, a}
\end{aligned}
$$

where $W_{s, a}$ is the weight of brood $s$ at accumulated term $a$ derived from age-length and weight-length relationships [8].

Hairtail caught by trolling line around the Bungo Channel were categorized into five commercial size grades (Makino et al., in press): mini (individuals of 200-250 g body weight), small (250-310 g), medium (310-420 g), large (420-630 g), and king (> $630 \mathrm{~g}$ ). According to the relative frequency of accumulated term $a$ of each seasonal brood in each size grade [8], catch in number of each grade (i) per recruitment for each lure $\left(\mathrm{GPR}_{i, t}\right)$ was calculated as follows:

$$
\begin{aligned}
G P R_{i, t}= & \sum_{S=1}^{2} \sum_{a=1}^{A_{s}} \frac{F_{s, a, T C(t)}}{F_{s, a, T C(t)}+F_{s, a, T D(t)}+F_{s, a, P C}+M} \\
& \times\left\{1-\exp \left(-F_{s, a, T C(t)}-F_{s, a, T D(t)}-F_{s, a, P C}-M\right)\right\} S_{s, a} P_{i, s, a}
\end{aligned}
$$

where $P_{i, s, a}$ is the proportion of size grade $i$ out of the total catch in number of brood $s$ at accumulated term $a$. 


\section{Results}

\section{Comparison of size composition and CPUE (individuals per hook)}

During the study period, the total number of hooks with each bait type was as follows: type-1, 2331 hooks; type-2, 16,863 hooks; type-3, 6890 hooks. The number of hairtail caught was as follows: type-1, 958 individuals; type-2, 1991 individuals; type-3, 1738 individuals. The CPUE in total was as follows: type-1, 0.41 (individuals/hook); type-2, 0.12 ; type- $3,0.25$. The proportion of undersize individuals ( $\mathrm{PAL}<25 \mathrm{~cm}$ ) out of the total catch of each lure was as follows: type-1, 27\%; type-2, 9\%; and type-3, 10\% (Fig. 3).

For type-1, the CPUE for each size class (interval of $1 \mathrm{~cm}$ ) increased from PAL $17 \mathrm{~cm}$ and the maximum value (approximately 0.050) was around PAL $25 \mathrm{~cm}$ (Fig. 4). The CPUE for PAL $<30 \mathrm{~cm}$ was higher for type- 1 than for type- 2 and type- 3 . The CPUE of type- 2 for PAL $<20 \mathrm{~cm}$ was 0.0 , and the maximum was 0.012 for PAL $29 \mathrm{~cm}$. The CPUE values of type-2 for all size classes were lower than those of the other lure types. The CPUE of type- 3 for size class PAL $<20 \mathrm{~cm}$ was 0.0 , and the maximum (approx. 0.027) was around PAL $28 \mathrm{~cm}$. The CPUE of type- 3 for PAL $>30 \mathrm{~cm}$ was almost the same as that of type- 1 .

The ratios of CPUE of type- 2 and type- 3 for each size class to the CPUE of type-1 are plotted in Fig. 5. The ratio of type-2 CPUE to type-1 CPUE for all size classes was always less than 1.0. The ratio of type-3 CPUE to type-1 CPUE for PAL $<34 \mathrm{~cm}$ was less than 1.0, but was more than 1.0 for PAL $>34 \mathrm{~cm}$. From these ratios, the following equations were calculated (ratios for size classes $>36 \mathrm{~cm}$ PAL were not used because of small sample size)

$y_{1}=0.042 x-0.79$
$y_{2}=0.068 x-1.24$

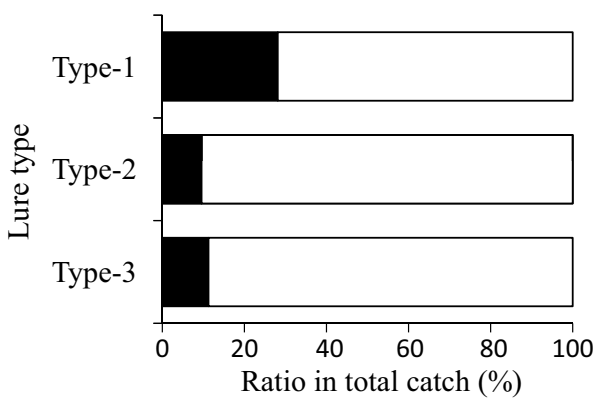

- Under commercial size $\square$ Commercial size

Fig. 3 Relative frequency of commercial-size and undersize fish caught by type- 1 , type- 2 , and type- 3 in the field

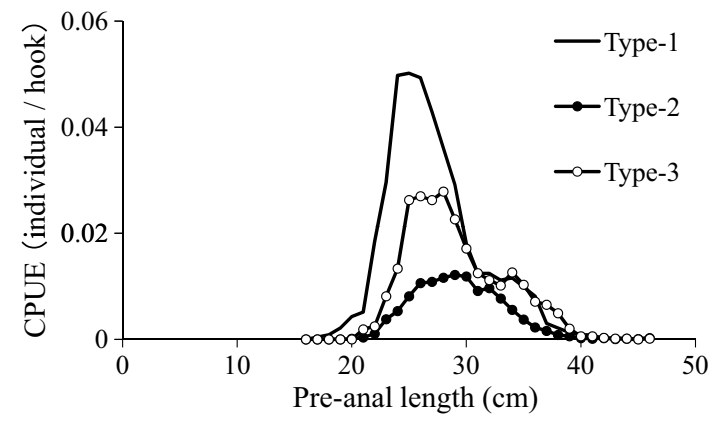

Fig. 4 Catch per unit effort (CPUE; individuals/hook) of each lure for every pre-anal-length (PAL) size class of hairtail caught by each lure in the field

where $x$ is the PAL of hairtail, $y_{1}$ is the ratio of the CPUE of type- 2 to that of type- 1 , and $y_{2}$ is the ratio of the CPUE of type- 3 to that of type- 1 .

\section{NPR, YPR, and composition of commercial size GPR}

The ratios of NPR and YPR of type-2 and type- 3 to those of type- 1 are shown in Fig. 6 . The NPR values were 0.54 for type- 2 and 0.78 for type- 3 , and the YPR values were 0.77 for type- 2 and 1.02 for type-3.

Figure 7 shows the relative composition of commercial size GPR for each lure. There were more mini-size fish in the catch from type- 1 than in the catches from type- 2 and type-3. In contrast, there were more king-size fish in the catches from type- 2 and type- 3 than in the catch from type1. The relative values of mini-size fish were $0.28,0.05$ and 0.09 from type- 1 , type- 2 and type-3, respectively. On the other hand, those of king-size fish were $0.20,0.22$ and 0.27 , respectively.

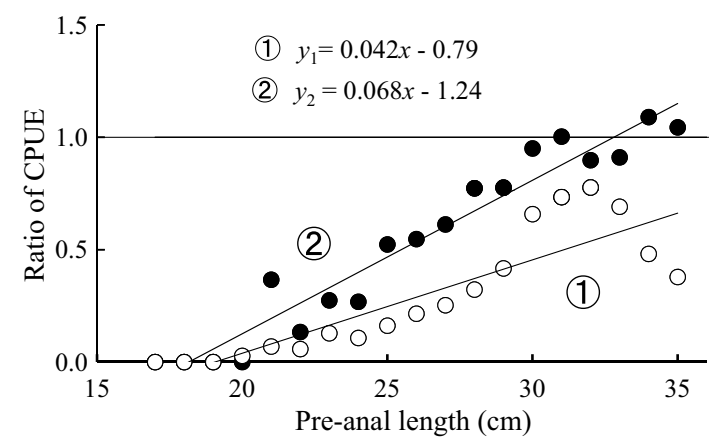

Fig. 5 Ratio of CPUE of type-2 and type-3 to that of type-1 for every PAL size class. White dots Ratio of CPUE of type- 2 to type-1, black dots ratio of CPUE of type-3 to type-1. Regression lines derived from ratio of CPUE for type-2 and type- 3 for different PAL (the midpoint of each PAL size class) 


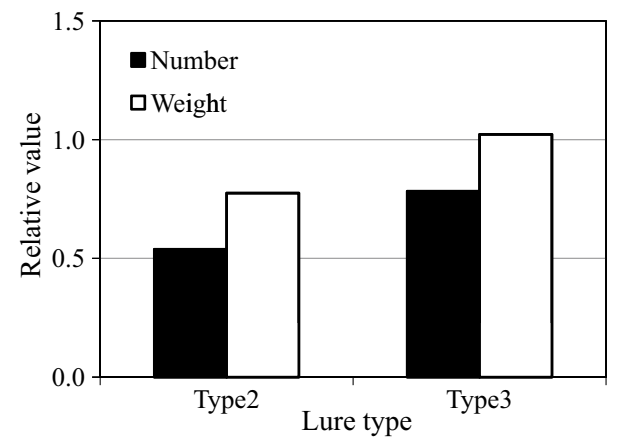

Fig. 6 Relative catch in number per recruitment (NPR) and yield per recruitment of type- 2 and type- 3 to those of type- 1

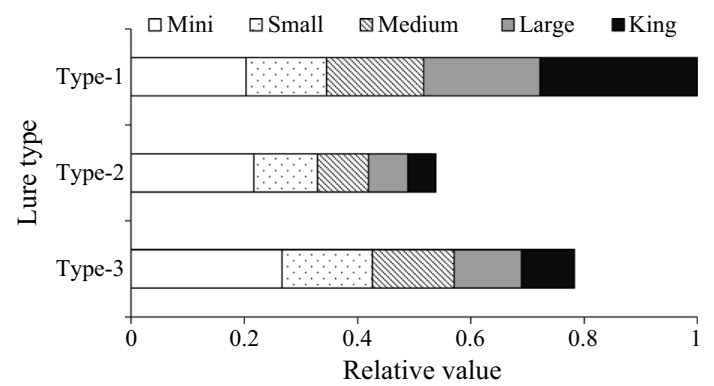

Fig. 7 Relative composition of commercial size grades based on relative NPR (catch in NPR) of the catch from type-1, type-2, and type3. Mini Individual body weight $200-250 \mathrm{~g}$, Small individual body weight $250-310 \mathrm{~g}$, Medium individual body weight $310-420 \mathrm{~g}$, Large individual body weight 420-630 g, King individual body weight $>630 \mathrm{~g}$

\section{Discussion}

Use of the new types of bait (type-2 and type-3) reduced the catch rate of small hairtail. Larger hairtail were captured efficiently by larger bait (type-3), but smaller bait (type-1) also caught large hairtail to some extent (Fig. 4). While optimal prey size generally increases as the body size of a fish species increases, larger fish target a wider size range of prey [9-12]. In contrast, smaller fish can feed only on small prey. This is the most likely explanation for the difference in size composition of hairtail among the bait types in our study. A similar relationship between artificial bait size and captured fish size was reported for Atlantic cod Gadus morhua [13, 14], and Løkkeborg [13] came to the same conclusions as us. Hairtail changes its prey type depending on its growth stage, and hairtail with body sizes the same as those in this study have been shown to feed mainly on fish species [15, 16]. Although a change in optimal prey size depending on the size of the piscivorous hairtail has not been reported previously, the different bait sizes in this study appeared to influence its feeding preferences.
The recruitment and growth of the hairtail population around the Bungo Channel have been affected by overfishing in recent years $[5,6]$. Around the Bungo Channel, the biological minimum size of female hairtail is $20 \mathrm{~cm}$ PAL, and length at 50 and $100 \%$ maturity is approximately 25 and $35-\mathrm{cm}$ PAL, respectively [17]. Compared with type-1, type-2 or type-3 caught fewer hairtail of $<20$-cm PAL, and fewer hairtail at 50\% maturity (as estimated from PAL). That is, use of type- 2 and type- 3 effectively enables fishers to avoid discarding fish and helps to conserve immature hairtail.

In Usuki, captured hairtail are sorted by size and packed into $5-\mathrm{kg}$ boxes. Thus, there are more than twice as many boxes of king-size hairtail ( 8 individuals or fewer/box) as mini-size hairtail (21-25 individuals/box) if the same numbers of fish in each size class are caught. Larger hairtail command a higher price; for example, the price of a box of king-size fish is more than three times that of a box of mini-size fish [18], thus the price of a king-size fish is more than six times that of a mini-size fish. By using type- 2 and type-3, fewer mini- and small-size fish and more large- and king-size fish were caught, so the value of the catch increased. The growth rate of hairtail is relatively rapid, and mini-size fish reach large and king size within 1 or 2 years $[8,18]$, thus use of type- 2 and type- 3 improves conditions for hairtail growth with limited effects on the income of fisher households.

The newly developed artificial bait has been sold to, and gradually adopted by, the trolling line fishers around the Bungo Channel. If all fishers use only the new bait around the Bungo Channel, it will be effective for the recovery of the hairtail stock in this area. Dominant year classes of hairtail occur occasionally around the Bungo Channel [4]. If the new bait is used when fish are young and small after the recruitment of a dominant year class, then this will accelerate restoration of the catch-size stock. It is thought that type-3 will be readily accepted by fishers because the YPR is higher for this type of lure than for the traditional lure (type-1), and type- 3 will have a limited effect on income. On the other hand, the acceptance of type-2 will be difficult because of its lower fishing efficiency. However, the use of type- 2 should be considered if the stock level of hairtail around the Bungo Channel continues to decrease.

Acknowledgements We thank Captain K. Ando of the trolling line fishing boat Koryo-maru and Mr A. Hikida of JF Oita for their assistance with sampling. We also thank H. Nagaoka and T. Orimoto of Marukyu for developing the new artificial bait. We are indebted to the staff of the Japan Marine Fishery Resources Research Center for their support during this study. Our special posthumous thanks go to the late Captain T. Takahashi of the trolling line fishing boat Horyo-maru for his co-operation with this study. 
Open Access This article is distributed under the terms of the Creative Commons Attribution 4.0 International License (http://creativecommons.org/licenses/by/4.0/), which permits unrestricted use, distribution, and reproduction in any medium, provided you give appropriate credit to the original author(s) and the source, provide a link to the Creative Commons license, and indicate if changes were made.

\section{References}

1. Yamada T, Tokimura M, Horikawa H, Nakabo T (2007) Hairtail Trichiurus japonicus Temminck and Schlegel. In: Fishes and fisheries of the East China and Yellow Seas. Tokai University Press, Hadano, pp 962-972 (in Japanese)

2. Japan Marine Fishery Resources Research Center (2013) Report of the development of marine fishery resource (trolling line: hairtail around the Bungo Channel). Fisheries Research Agency, Yokohama (in Japanese)

3. Sakurai M, Hirose T, Hidaka K, Tsuru S, Kurosaka K, Okaya K, Ogawa M (2015) On the trend of catch at home and abroad and the position of trolling line fishery. Bull Jpn Soc Fish Oceanogr 79:184-185 (in Japanese)

4. Watari S, Tokumitsu S, Hirose T, Ogawa M (2017) Stock structure and resource management of hairtail Trichiurus japonicus based on seasonal broods around the Bungo Channel, Japan. Fish Sci. doi:10.1007/s12562-017-1140-y

5. Tokumitsu S, Hashida D, Hotta T (2013) Resource analysis of hairtail Trichiurus japonicas in the Bungo Channel and the surrounding sea in Japan. Fish Biol Oceanogr Kurosio 14:93-97 (in Japanese)

6. Prefecture Oita (2007) The resource recovery plan for hairtail in Oita Prefecture. Oita Prefecture, Oita (in Japanese)

7. Japan Marine Fishery Resources Research Center (2014) Report of the development of marine fishery resource (trolling line: hairtail around the Bungo Channel). Fisheries Research Agency, Yokohama (in Japanese)
8. Watari S, Tokumitsu S, Hirose T, Ogawa M (2014) Age and size brand of the hairtail by spring and autumn brood in the Bungo Channel and Iyo-nada, Japan. Fish Biol Oceanogr Kurosio 15:7580 (in Japanese)

9. Werner EE (1974) The fish size, prey size, handling time relation in several sunfishes and some implications. J Fish Res Board Can 31:1531-1536

10. Kislalioglu M, Gibson RN (1976) Prey 'handling time' and its importance in food selection by the 15-spined stickleback, Spinachia spinachia (L.). J Exp Mar Biol Ecol 25:115-158

11. Wootton RJ (1990) Feeding ecology of teleost fish. Chapman and Hall, London, pp 32-72

12. Sawara Y (2010) Foraging ecology. In: Tsukamoto K (ed) The Basis on Fish Ecology. Kouseisha-kouseikaku, Tokyo, pp 204213 (in Japanese)

13. Løkkeborg S (1990) Reduced catch of under-sized cod (Gadus morhua) in longlining by using artificial bait. Can J Fish Aquat Sci 47:1112-1115

14. Løkkeborg S, Bjordal $\AA$ (1992) Species and size selectivity in longline fishing: a review. Fish Res 13:311-322

15. Munekiyo M, Kuwahara A (1985) Food habits of ribbon fish in the Western Wakasa Bay. Nippon Suisan Gakkaishi 51:913-919 (in Japanese with English abstract)

16. Chiou WD, Chen CY, Wang CM, Chen CT (2006) Food and feeding habits of ribbonfish Trichiurus lepturus in coastal waters of south-western Taiwan. Fish Sci 72:373-381

17. Yanagawa S (2009) Fisheries biology of hairtail Trichiurus japonicus around the Bungo Channel. PhD dissertation, Tokyo University of Marine Science and Technology, Tokyo (in Japanese)

18. Makino M, Watari S, Hirose T, Oda K, Takei A, Ogawa M, Horikawa H (2017) A transdisciplinary study of coastal fisheries co-management: a case study of the hairtail Trichiurus japonicus trolling line fishery around the Bungo Channel, Japan. Fish Sci. doi:10.1007/s12562-017-1141-x 